\title{
Rapid enantiomeric separation of polychlorinated biphenyls by electrokinetic chromatography using mixtures of neutral and charged cyclodextrin derivatives
}

\author{
C. García-Ruiz, Y. Martín-Biosca, A.L. Crego, M.L. Marina* \\ Departamento de Química Analítica, Facultad de Química, Universidad de Alcalá, Ctra. Madrid-Barcelona Km. 33.600, \\ 28871 Alcalá de Henares (Madrid), Spain
}

Received 14 July 2000; received in revised form 19 October 2000; accepted 20 November 2000

\begin{abstract}
Electrokinetic chromatography with cyclodextrin derivatives (CD-EKC) was used to achieve the rapid enantiomeric separation of chiral polychlorinated biphenyls (PCBs). Thirteen of the 19 chiral PCBs stable at room temperature were individually separated into their two enantiomers by using 2-morpholinoethanesulfonic acid (MES) buffer (pH 6.5) containing carboxymethylated $\gamma$-cyclodextrin $(\mathrm{CM}-\gamma-\mathrm{CD})$ as pseudostationary phase mixed with $\beta$-cyclodextrin $(\beta-\mathrm{CD})$ or permethylated $\beta$-cyclodextrin (PM- $\beta-C D$ ). Urea was also added to increase the solubility of PCBs and cyclodextrins in the aqueous separation buffer. Several experimental parameters such as the nature, concentration, and $\mathrm{pH}$ of the buffer, nature and concentration of the cyclodextrin derivatives used, and the addition of different additives were studied in order to improve the enantiomeric separation. In addition, the effect of some instrumental parameters such as separation temperature and applied voltage was also investigated. PCBs were enantiomerically separated in less than $12 \mathrm{~min}$ by using a $50 \mathrm{~m} M$ MES buffer ( $\mathrm{pH}$ 6.5) containing $20 \mathrm{~m} M$ CM- $\gamma-\mathrm{CD}, 10 \mathrm{~m} M \beta-\mathrm{CD}$ or $20 \mathrm{~m} M$ PM- $\beta-\mathrm{CD}$, and $2 M$ urea at a temperature of $45^{\circ} \mathrm{C}$ and an applied voltage of $20 \mathrm{kV}$. (C) 2001 Elsevier Science B.V. All rights reserved.
\end{abstract}

Keywords: Enantiomer separation; Buffer composition; Polychlorinated biphenyls; Cyclodextrins

\section{Introduction}

Polychlorinated biphenyls (PCBs) represent an important class of priority pollutants due to their persistence, toxicity and bioaccumulation $[1,2]$. The enantiomeric separation of chiral PCBs is of special relevance because each enantiomer may have different toxicity, activity or metabolic pathways. More-

\footnotetext{
*Corresponding author. Tel.: +34-91-8854-935; fax: +34-918854-971.

E-mail address: mluisa.marina@uah.es (M.L. Marina).
}

over, although biologically active chiral compounds are introduced into the environment as racemates, their uptake and metabolism by an organism may be selective for enantiomers [3,4]. Therefore, it is very important to develop analytical methods enabling the enantiomeric separation of chiral PCBs.

Gas chromatography (GC), usually employed to separate PCB congeners, has also been employed to perform the separation of chiral PCBs [5-11]. Nevertheless, the characteristics of capillary electrophoresis (CE) techniques (high separation efficiency and flexibility) make this technique competitive with 
GC in the field of the enantiomeric separations [12]. Prior to this work, a mode of $\mathrm{CE}$, cyclodextrinmodified micellar electrokinetic chromatography (CD-MEKC) has been employed for the enantiomeric separation of chiral PCBs [13-16]. In fact, 12 PCBs (IUPAC numbers 45, 84, 88, 91, 95, 132, 136, $139,149,171,183$ and 196) were separated each one into its two enantiomers using sodium dodecyl sulfate (SDS) in 2-( $N$-cyclohexylamino)ethanesulfonic acid (CHES) buffer ( $\mathrm{pH} 10)$ containing $2 M$ urea and $\gamma$-cyclodextrin $(\gamma$-CD) [13] or mixtures of $\beta$ - and $\gamma$-CD as chiral modifiers [14]. On the other hand, chiral separations of PCBs 131, 135, 144, and 175 along with other seven chiral PCBs described before were obtained using a borate buffer $(\mathrm{pH} 9)$ containing also SDS and $\gamma-\mathrm{CD}$, but with a higher concentration of urea $(5 M)$ [15]. The above-mentioned group of $15 \mathrm{PCBs}$ were also enantiomerically separated by CD-MEKC using a mixed micellar system bile salt-SDS with $\gamma$-CD [16]. Finally, the possibilities of using bile salts alone as chiral surfactant in MEKC to achieve the enantiomeric separation of chiral PCBs were investigated [17].

If micelles are not added to the electrolyte solution, the separation of electrically neutral compounds (such as PCBs) can also be achieved by CE using charged cyclodextrins alone or mixed with neutral CDs. In this type of electrokinetic chromatography (EKC), named cyclodextrin electrokinetic chromatography (CD-EKC), the charged cyclodextrin acts as pseudostationary phase $[12,18]$. As in other modes of $\mathrm{CE}$, the enantioselectivity of this chiral pseudostationary phase can be modified using various chiral additives $[19,20]$, with several types of cyclodextrin derivatives (neutral and charged) the most used in the last few years [21,22].

The purpose of this work was to study the possibilities of CD-EKC with a charged cyclodextrin as chiral pseudostationary phase alone or mixed with a neutral cyclodextrin as chiral additive to achieve the enantiomeric separation of a group of chiral PCBs. The influence of the nature, concentration and $\mathrm{pH}$ of the buffer, as well as the nature and concentration of the cyclodextrin derivatives used and the addition of several organic additives (methanol, butanol, and urea) on the enantiomeric separation of PCBs was investigated. The effect of other experimental parameters such as temperature and ap- plied voltage was also studied in order to improve the resolution obtained between the enantiomers of chiral PCBs.

\section{Experimental}

\subsection{Reagents}

All reagents employed were of analytical grade. CHES was purchased from Sigma (St. Louis, MO, USA); 2-morpholinoethanesulfonic acid (MES), sodium dihydrogenphosphate dihydrate, butanol $(\mathrm{BuOH})$, dimethylformamide (DMF), and sodium hydroxide were supplied by Merck (Darmstadt, Germany); ammonium acetate, $\beta-\mathrm{CD}, \gamma-\mathrm{CD}$, and urea were from Fluka (Buchs, Switzerland); carboxymethylated $\gamma$-cyclodextrin [CM- $\gamma-\mathrm{CD}$, degree of substitution (D.S.) 3], carboxymethylated $\beta$-cyclodextrin (CM- $\beta-\mathrm{CD}$, D.S. 3), and permethylated $\beta$ cyclodextrin (PM- $\beta$-CD, D.S. $\sim 12-13$ ) were obtained from Cyclolab (Budapest, Hungary); methanol $(\mathrm{MeOH})$ was from Lab Scan (Dublin, Ireland). Water used to prepare solutions was purified through a Milli-Q system from Millipore (Bedford, MA, USA). All solutions were filtered prior use through $0.45-\mu \mathrm{m}$ pore size disposable nylon filters from Scientific Resources (Eatontown, NJ, USA).

The 19 PCBs studied were supplied by Dr. Ehrenstorfer Reference Materials (Augsburg, Germany). Table 1 shows the basic structures and IUPAC numbers of the compounds used throughout this study according to Ballschmiter and Zell nomenclature [23].

\subsection{Apparatus}

A HP ${ }^{3 \mathrm{D}} \mathrm{CE}$ system (Hewlett-Packard, Waldbronn, Germany) equipped with an on-column diode array detection (DAD) system and HP 3D-CE Chemstation software was used. Separations were performed on uncoated fused-silica capillaries of inner diameter (I.D.) $50 \mu \mathrm{m}$ and outer diameter (O.D.) $375 \mu \mathrm{m}$, purchased from Composite Metal Services (Worcester, UK). Capillaries had a total length of $58.5 \mathrm{~cm}$ and a length of $50 \mathrm{~cm}$ to the detector. Capillary 
Table 1

Basic structure, systematic names and IUPAC numbers (according to Ballschmitter and Zell nomenclature [23]) for the chiral PCBs studied

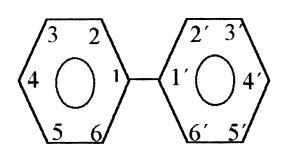

\begin{tabular}{|c|c|}
\hline PCB name & IUPAC number \\
\hline 2,2',3,6-Tetrachlorobiphenyl & 45 \\
\hline $2,2^{\prime}, 3,3^{\prime}, 6$-Pentachlorobiphenyl & 84 \\
\hline $2,2^{\prime}, 3,4,6$-Pentachlorobiphenyl & 88 \\
\hline $2,2^{\prime}, 3,4^{\prime}, 6$-Pentachlorobiphenyl & 91 \\
\hline $2,2^{\prime}, 3,5^{\prime}, 6$-Pentachlorobiphenyl & 95 \\
\hline $2,2^{\prime}, 3,3^{\prime}, 4,6-$ Hexachlorobiphenyl & 131 \\
\hline $2,2^{\prime}, 3,3^{\prime}, 4^{\prime}, 6-$ Hexachlorobiphenyl & 132 \\
\hline $2,2^{\prime}, 3,3^{\prime}, 5^{\prime}, 6-$ Hexachlorobiphenyl & 135 \\
\hline $2,2^{\prime}, 3,3^{\prime}, 6,6^{\prime}$-Hexachlorobiphenyl & 136 \\
\hline $2,2^{\prime}, 3,4,4^{\prime}, 6-$ Hexachlorobiphenyl & 139 \\
\hline $2,2^{\prime}, 3,4,5^{\prime}, 6-$ Hexachlorobiphenyl & 144 \\
\hline $2,2^{\prime}, 3,4^{\prime}, 5^{\prime}, 6-$ Hexachlorobiphenyl & 149 \\
\hline $2,2^{\prime}, 3,3^{\prime}, 4,4^{\prime}, 6$-Heptachlorobiphenyl & 171 \\
\hline $2,2^{\prime}, 3,3^{\prime}, 4,5,6^{\prime}-$ Heptachlorobiphenyl & 174 \\
\hline $2,2^{\prime}, 3,3^{\prime}, 4,5^{\prime}, 6$-Heptachlorobiphenyl & 175 \\
\hline $2,2^{\prime}, 3,3^{\prime}, 4,6,6^{\prime}-$ Heptachlorobiphenyl & 176 \\
\hline $2,2^{\prime}, 3,4,4^{\prime}, 5^{\prime}, 6-$ Heptachlorobiphenyl & 183 \\
\hline $2,2^{\prime}, 3,3^{\prime}, 4,4^{\prime}, 5^{\prime}, 6-$-Octachlorobiphenyl & 196 \\
\hline $2,2^{\prime}, 3,3^{\prime}, 4,4^{\prime}, 6,6^{\prime}$-Octachlorobiphenyl & 197 \\
\hline
\end{tabular}

temperature was varied from 25 to $60^{\circ} \mathrm{C}$ and $\mathrm{UV}$ detection was performed at $230 \mathrm{~nm}$.

Electrolytic solutions were degassed in an ultrasonic bath KM from Raypa (Barcelona, Spain). A $654 \mathrm{pH}$ meter from Metrohm (Herisau, Switzerland) was employed to adjust the $\mathrm{pH}$ of the separation buffers.

\subsection{Procedure}

Separation buffers were prepared by dissolving the appropriate amount of buffer, $\mathrm{CD}$ derivatives, and urea into water to achieve the desired concentration, adding in some cases adequate aliquots of liquid additives (methanol or butanol) prior to the addition of water. Finally, the $\mathrm{pH}$ was adjusted to 6.5 with 1 $M$ or $0.1 M$ sodium hydroxide solution for MES buffer, with $1 M$ or $0.1 M \mathrm{NH}_{3}$ solution for ammonium acetate buffer or with $1 M$ hydrochloric acid for phosphate buffer prior to obtain the final volume.
Sample solutions were prepared by dissolving each PCB in DMF to achieve a final concentration of 200 ppm approximately.

Before first use, a new capillary was rinsed with 1 $M \mathrm{NaOH}$ for $30 \mathrm{~min}$, followed by a 30-min rinse with water. Between introduction of samples, the capillary was conditioned with water for $2 \mathrm{~min}, 0.1$ $M \mathrm{NaOH}$ for $2 \mathrm{~min}$, water for $2 \mathrm{~min}$ and separation buffer for $2 \mathrm{~min}$. Injections were made by pressure (from $50 \mathrm{mbar}$ for $1.2 \mathrm{~s}$ to $20 \mathrm{mbar}$ for $1 \mathrm{~s}$ ). For separation, voltages between 15 and $25 \mathrm{kV}$ were used and the detection took place at $230 \mathrm{~nm}$. At the end of the day the capillary was rinsed with water for 2 $\min , 0.1 M \mathrm{NaOH}$ for $2 \mathrm{~min}$ and water for $2 \mathrm{~min}$, then stored in water. The conditioning method was used to obtain good peak shapes and reproducible retention data.

\section{Results and discussion}

All chiral PCBs stable at ambient temperature (19) were injected into a $\mathrm{CE}$ system using charged $\mathrm{CD}$ derivatives alone or mixed with neutral $\mathrm{CD}$ derivatives in the separation buffer to perform their enantioseparation by CD-EKC. The type of buffer without and with additives (methanol, butanol and urea), and some instrumental parameters such as separation temperature and applied voltage were also varied.

\subsection{CD-EKC using charged cyclodextrins alone}

$\mathrm{CM}-\gamma-\mathrm{CD}$ and $\mathrm{CM}-\beta-\mathrm{CD}$ were used at concentrations ranging from 5 to $50 \mathrm{~m} M$ (five values, 5,10 , $20,30,50 \mathrm{mM})$ in the case of CM- $\gamma-\mathrm{CD}$ and from 10 to $20 \mathrm{~m} M$ for $\mathrm{CM}-\beta-\mathrm{CD}$ (two values). Two $\mathrm{pH}$ values were tested using different buffers: $\mathrm{pH} 9$ using a $50 \mathrm{~m} M$ CHES buffer and $\mathrm{pH} 6.5$ using 50 $\mathrm{m} M$ ammonium acetate or $50 \mathrm{~m} M$ MES buffers. Concentrations ranging from 10 to $50 \mathrm{~m} M$ in CM- $\gamma$ $\mathrm{CD}$ were also tested at $\mathrm{pH} 6.5$ (50 $\mathrm{m} M$ MES buffer) using $1 \%$ and $5 \%$ methanol, $1 \% n$-butanol or $2 M$ urea as additives. In all these experiments an applied voltage of $20 \mathrm{kV}$ and a temperature of $25^{\circ} \mathrm{C}$ were employed. Under any of these experimental conditions the chiral recognition of PCBs was achieved. However, since the use of $\mathrm{CM}-\boldsymbol{\gamma}-\mathrm{CD}$ enabled the 
obtention of a peak for a higher number of PCBs (one single peak) than $\mathrm{CM}-\beta-\mathrm{CD}, \mathrm{CM}-\gamma-\mathrm{CD}$ was chosen in order to study the potential of using mixtures of this charged $\mathrm{CD}$ and neutral $\mathrm{CDs}$ to perform the chiral separation of PCBs. A value of $\mathrm{pH}$ equal to 6.5 was also chosen because at $\mathrm{pH} 9$ the electroosmotic flow was much too high and the elution window was very small. In addition, MES buffer was preferred instead of ammonium acetate buffer because the latter generated higher current intensity values than MES buffer.

\subsection{CD-EKC using mixtures of charged and neutral cyclodextrins}

The use of different neutral cyclodextrins $(\gamma-\mathrm{CD}$, $\beta-C D$ or $P M-\beta-C D)$ as chiral additives in the separation buffer containing $\mathrm{CM}-\gamma-\mathrm{CD}$ was studied in order to achieve the enantiomeric separation of chiral PCBs (see Table 2). Urea $(2 M)$ was also added because it was shown that the shape of peaks improved under these conditions probably due to a better solubilization of PCBs and CDs in the aqueous buffer. When mixtures of $30 \mathrm{~m} M \mathrm{CM}-\gamma-\mathrm{CD}$ with different concentrations of $\gamma$-CD $(20,30$, or $40 \mathrm{mM})$ were employed, none of the PCBs studied were enantiomerically separated. These results show that $\gamma-\mathrm{CD}$ is not a good chiral additive in the CD-EKC system described. However, when $\beta-\mathrm{CD}$ or PM- $\beta$ $\mathrm{CD}$ were used as chiral additives, several chiral PCBs were enantiomerically separated using $20 \mathrm{mM}$ or $30 \mathrm{~m} M \mathrm{CM}-\gamma-\mathrm{CD}$ as pseudostationary phase (see Table 2). When $\beta$-CD was used up to 12 of the 19 chiral PCBs $(45,88,91,95,131,132,136,139,144$, 149,171 and 176) were enantiomerically resolved, while the use of PM- $\beta-C D$ only enabled the enantioseparation of eight chiral PCBs $(45,88,91,95,131$, 136,144 and 197). Although the use of PM- $\beta-C D$ enabled the enantiomeric separation of a lower number of PCBs, this $\mathrm{CD}$ derivative allowed the enantioseparation of PCB 197 that was not possible using $\beta-C D$ as chiral additive. Furthermore, it is the first time that PCB 197 is separated into its two enantiomers by CE (see Fig. 1a), and although it was only partially resolved $\left(R_{s}=0.8\right)$, this PCB has only been partially separated by GC and high-performance liquid chromatography (HPLC) but in very long analysis times $[11,24]$. In fact, the partial enantior-

Table 2

Chiral PCBs enantioseparated, from the 19 chiral PCBs studied, using $50 \mathrm{~m} M$ MES buffer (pH 6.5) and $2 M$ urea with mixtures of $\mathrm{CM}-\gamma-\mathrm{CD}$, as pseudostationary phase, and several neutral CDs, as chiral additives ${ }^{\mathrm{a}}$

\begin{tabular}{|c|c|c|c|c|}
\hline $\begin{array}{l}\text { Charged CD } \\
\text { (pseudostationary phase) }\end{array}$ & $\begin{array}{l}\text { Neutral CD } \\
\text { (chiral additive) }\end{array}$ & $\begin{array}{l}\text { Temperature } \\
\left({ }^{\circ} \mathrm{C}\right)\end{array}$ & $\begin{array}{l}\text { Current intensity } \\
(\mu \mathrm{A})\end{array}$ & Chiral PCBs enantiomerically separated \\
\hline $30 \mathrm{~m} M \mathrm{CM}-\gamma-\mathrm{CD}$ & $\begin{array}{l}20 \mathrm{~m} M \gamma-\mathrm{CD} \\
30 \mathrm{~m} M \gamma-\mathrm{CD} \\
40 \mathrm{~m} M \gamma-\mathrm{CD}\end{array}$ & $\begin{array}{l}25 \\
25 \\
25\end{array}$ & $\begin{array}{l}115 \\
115 \\
115\end{array}$ & $\begin{array}{l}\text { None } \\
\text { None } \\
\text { None }\end{array}$ \\
\hline $30 \mathrm{~m} M \mathrm{CM}-\gamma-\mathrm{CD}$ & $40 \mathrm{~m} M \beta-\mathrm{CD}$ & $25 / 45$ & $115 / 150$ & 45,95 \\
\hline $20 \mathrm{~m} M \mathrm{CM}-\gamma-\mathrm{CD}$ & $\begin{array}{l}40 \mathrm{~m} M \beta-\mathrm{CD} \\
30 \mathrm{~m} M \beta-\mathrm{CD} \\
20 \mathrm{~m} M \beta-\mathrm{CD} \\
10 \mathrm{~m} M \beta-\mathrm{CD} \\
5 \mathrm{~m} M \beta-\mathrm{CD}\end{array}$ & $\begin{array}{l}45 \\
45 \\
25 / 45 / 60 \\
45 \\
45\end{array}$ & $\begin{array}{l}97 \\
97 \\
70 / 97 / 120 \\
97 \\
97\end{array}$ & $\begin{array}{l}45,95 \\
45,95,136 \\
45,88,91,95,136,144,149 \\
45,88,91,95,131,132,136,139,144,149,171,176 \\
45,88,91,95,131,132,136,139,144,149,171,176\end{array}$ \\
\hline $20 \mathrm{~m} M \mathrm{CM}-\gamma-\mathrm{CD}$ & $\begin{array}{l}10 \mathrm{~m} M \text { PM- } \beta-C D \\
20 \mathrm{~m} M \text { PM- } \beta-C D \\
40 \mathrm{~m} M \text { PM- } \beta-C D \\
60 \mathrm{~m} M \text { PM- } \beta-C D\end{array}$ & $\begin{array}{l}45 \\
45 \\
45 \\
45\end{array}$ & $\begin{array}{l}97 \\
97 \\
97 \\
97\end{array}$ & $\begin{array}{l}45,88,91,95,131,136,144 \\
45,88,91,95,131,136,144,197 \\
45,88,95,136 \\
45,88,95,136\end{array}$ \\
\hline $30 \mathrm{~m} M \mathrm{CM}-\gamma-\mathrm{CD}$ & $20 \mathrm{~m} M$ PM- $\beta-\mathrm{CD}$ & 45 & 150 & $45,88,91,95,131,144,197$ \\
\hline
\end{tabular}

\footnotetext{
${ }^{a}$ Current intensity is also included. Instrumental conditions: uncoated fused-silica capillary, $58.5 \mathrm{~cm}(50 \mathrm{~cm}$ to the detector $) \times 50 \mu \mathrm{m}$ I.D.; injection, $20 \mathrm{mbar}, 1 \mathrm{~s}$; applied voltage, $20 \mathrm{kV}$; and UV detection at $230 \mathrm{~nm}$.
} 

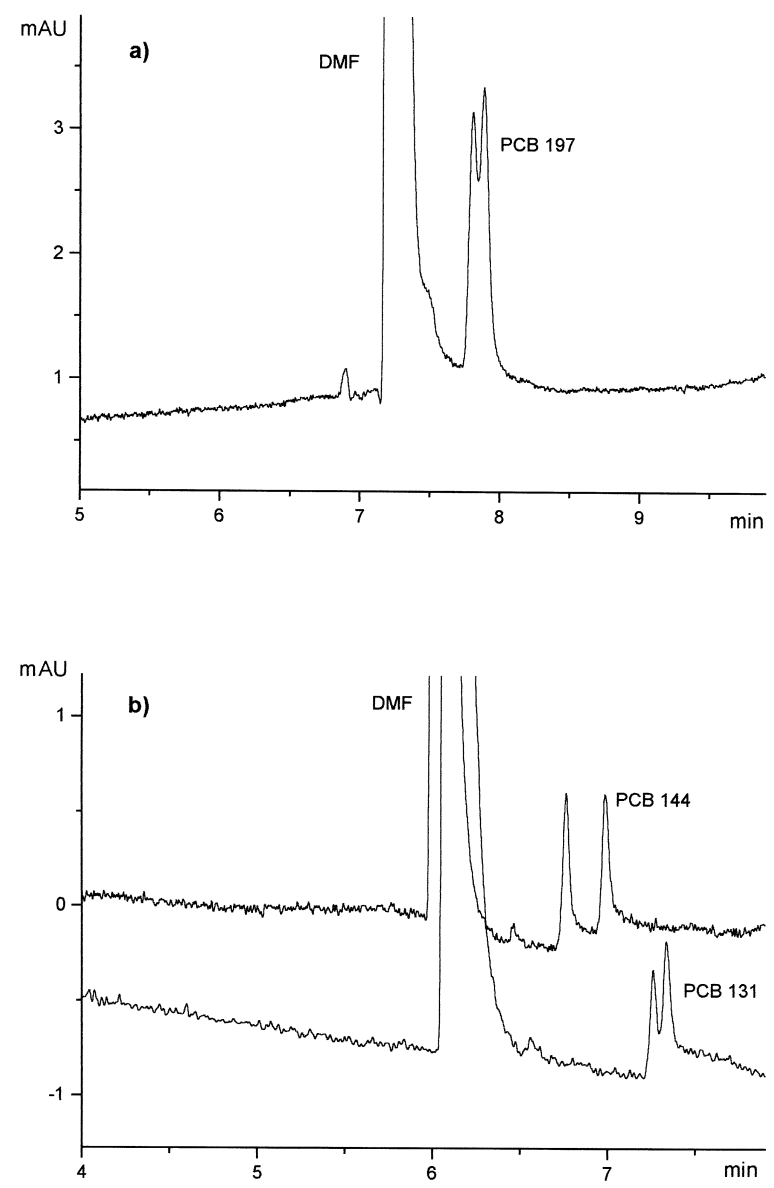

Fig. 1. Enantiomeric separation of PCBs 197, 144 and 131. Separation buffer: $50 \mathrm{~m} M$ MES (pH 6.5), $2 M$ urea, and $20 \mathrm{~m} M$ CM- $\gamma$-CD with (a) $20 \mathrm{~m} M$ PM- $\beta-C D$ and (b) $10 \mathrm{~m} M \beta-C D$. Injection by pressure, $20 \mathrm{mbar}$ for $1 \mathrm{~s}$. Capillary, $58.5 \mathrm{~cm}(50 \mathrm{~cm}$ to the detector $) \times 50 \mu \mathrm{m}$ I.D. Temperature, $45^{\circ} \mathrm{C}$. Applied voltage, $20 \mathrm{kV}(\sim 97 \mu \mathrm{A})$; UV detection at $230 \mathrm{~nm}$.

esolution $\left(R_{s}=0.7\right)$ of PCB 197 has recently been performed using a chiral capillary column (with hydroxypropyl-permethyltrifluroacetyl $\gamma$-cyclodextrin) by GC in an analysis time close to $60 \mathrm{~min}$ [11]. On the other hand, the use of a PM- $\beta-C D$ derivatized silica as chiral stationary phase in reversed-phase HPLC has allowed one to partially resolve PCB 197 $\left(R_{s}=0.8\right)$ in about $50 \mathrm{~min}$ [24]. These results seem to confirm that PM- $\beta-C D$ is a good chiral additive for the enantioseparation of highly hydrophobic compounds such as octachlorobiphenyl (PCB 197). In addition, although the chiral separations of PCBs 131 and 144 have previously been reported by CD-
MEKC [15,16], longer analysis times (between 15 and $25 \mathrm{~min}$ ) were required in contrast to the result described in this work (analysis time less than $8 \mathrm{~min}$ ) (see Fig. 1b). These chiral separations were also reported by $\mathrm{GC}[8,9]$ but in general very long analysis times were required (more than $1 \mathrm{~h}$ ). On the other hand, these results do not agree with those obtained by CD-MEKC $[13,14]$, in which $\gamma$-CD was more effective in the enantiomeric separation of chiral PCBs than $\beta-\mathrm{CD}$ due to the larger size of the cavity of $\gamma$-CD compared to $\beta-C D$. This different behavior between CD-MEKC and CD-EKC could be due to the formation of a ternary complex PCBsurfactant monomer-CD (demonstrated for other several solutes and surfactants [25]), which does not take place in CD-EKC. In addition, some authors believe that this ternary complex inside the $\gamma-\mathrm{CD}$ cavity may account for its effectiveness [26].

The enantiomeric resolutions obtained for chiral PCBs when the concentration of $\beta-C D$ was varied from 5 to $40 \mathrm{~m} M$ are shown in Fig. 2a. It can be observed that the best enantioresolution corresponds to $10 \mathrm{~m} M$ for PCBs $45,91,95,132,144,149$ and 171, whereas for PCBs 88, 131, 136, 139 and 176 the best resolution was achieved at $5 \mathrm{~m} M$ of $\beta-C D$. On the other hand, the best results obtained for all the chiral PCBs enantiomerically separated with PM$\beta-C D$ were achieved at a concentration of $20 \mathrm{mM}$ (see Fig. 2b). Using a constant concentration of $\beta-C D$ or $P M-\beta-C D$, similar results were obtained when $20 \mathrm{~m} M$ or $30 \mathrm{~m} M \mathrm{CM}-\gamma-\mathrm{CD}$ was employed. Then, a $20 \mathrm{~m} M$ concentration of $\mathrm{CM}-\boldsymbol{\gamma}-\mathrm{CD}$ was chosen in order to decrease the current intensity (up to $150 \mu \mathrm{A}$ with $30 \mathrm{~m} M \mathrm{CM}-\boldsymbol{\gamma}-\mathrm{CD}$ ). Fig. 2 also shows that the enantiomeric resolutions obtained for PCBs 45, 88, 91, 95, 131, 136 and 144 were better with $\beta-C D$ than with PM- $\beta-C D$ and generally better with $10 \mathrm{~m} M$ than with $5 \mathrm{~m} M$ of $\beta-C D$.

The effect of the temperature and the applied voltage on the enantioseparation of PCBs was also studied in this work. Temperatures of 25,45 and $60^{\circ} \mathrm{C}$ and applied voltages of 15,20 and $25 \mathrm{kV}$ were employed for the best conditions selected $[50 \mathrm{mM}$ MES buffer (pH 6.5), $2 M$ in urea, $20 \mathrm{~m} M$ in $\mathrm{CM}-\gamma-\mathrm{CD}$ and $10 \mathrm{~m} M$ in $\beta-\mathrm{CD}]$. An increase in the temperature or applied voltage did not produce a significant effect on the enantioresolution except for PCBs 95 and 136. For PCB 95 an increment in the 

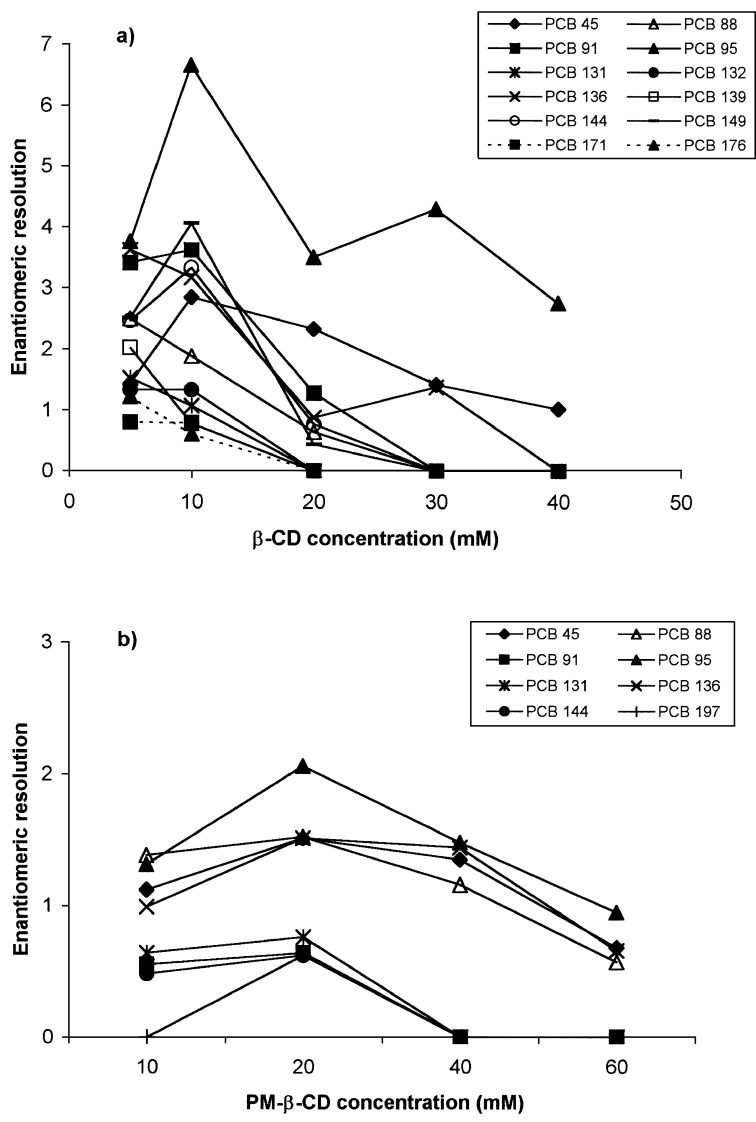

Fig. 2. Enantiomeric resolution of chiral PCBs as a function of (a) $\beta-\mathrm{CD}$ concentration; (b) PM- $\beta-\mathrm{CD}$ concentration. Other conditions as in Fig. 1.

temperature or voltage drives to a decrease in the enantioresolution. In the case of PCB 136 the contrary effect was observed, that is, enantiomeric resolution increased when increasing the temperature or the applied voltage. On the other hand, an increase in the temperature or the applied voltage produced a decrease in the analysis time but an increase in the current intensity (data not shown). Therefore, $45^{\circ} \mathrm{C}$ and $20 \mathrm{kV}$ were chosen as good compromise among enantioresolution, analysis time and current intensity. Under these conditions, the simultaneous enantiomeric separation of mixtures of chiral PCBs were performed.

Two examples of multicomponent separations are shown in Fig. 3. In Fig. 3a a mixture of up to five PCBs $(45,88,91,95$ and 176) was separated by
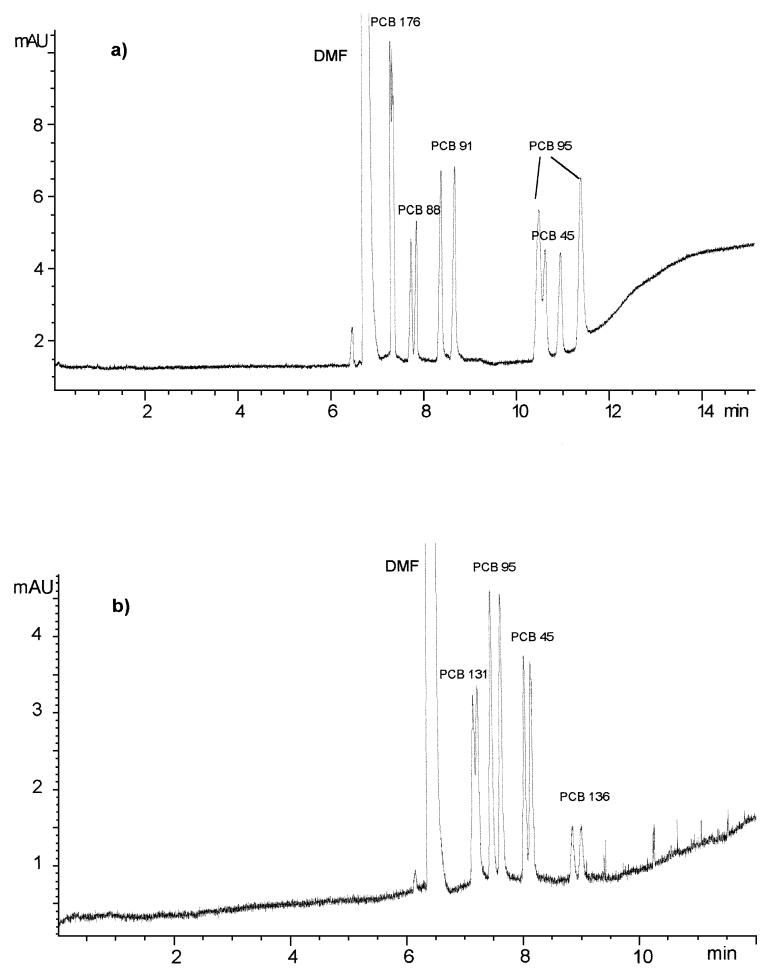

Fig. 3. (a) Electropherogram corresponding to the chiral separation of a mixture of PCBs 176, 88, 91, 95 and 45 by CD-EKC using a $50 \mathrm{~m} M$ MES buffer ( $\mathrm{pH}$ 6.5) containing $2 M$ urea, $20 \mathrm{~m} M$ $\mathrm{CM}-\gamma-\mathrm{CD}$, and $10 \mathrm{~m} M \quad \beta-\mathrm{CD}$. (b) Electropherogram corresponding to the chiral separation of a mixture of PCBs 131, 95, 45 and 136 by CD-EKC using a $50 \mathrm{~m} M$ MES buffer (pH 6.5) containing $2 M$ urea, $20 \mathrm{~m} M \mathrm{CM}-\gamma-\mathrm{CD}$, and $20 \mathrm{~m} M$ PM- $\beta-C D$. Other conditions as in Fig. 1.

CD-EKC into all their 10 enantiomers in less than 12 min, using $20 \mathrm{~m} M \mathrm{CM}-\gamma-\mathrm{CD}$ as pseudostationary phase and $10 \mathrm{~m} M \beta-\mathrm{CD}$ as chiral additive. Fig. $3 \mathrm{~b}$ shows the enantiomeric separation of four PCBs (45, 95, 131 and 136) in only $9 \mathrm{~min}$, using $20 \mathrm{mM}$ $\mathrm{CM}-\boldsymbol{\gamma}-\mathrm{CD}$ as pseudostationary phase and $20 \mathrm{~m} M$ PM- $\beta-C D$ as chiral additive. In both separations the analysis time is smaller than that obtained by CDMEKC (between 20 and $40 \mathrm{~min}$ ) [13-16], but a smaller number of PCBs can be separated simultaneously because the separation window is wider when a CD-MEKC system is used. Other separations of chiral PCBs $(132,139,149$ and 171) are shown in Fig. 4, being in all cases the analysis time significantly smaller than that obtained with CD-MEKC [13-16]. 

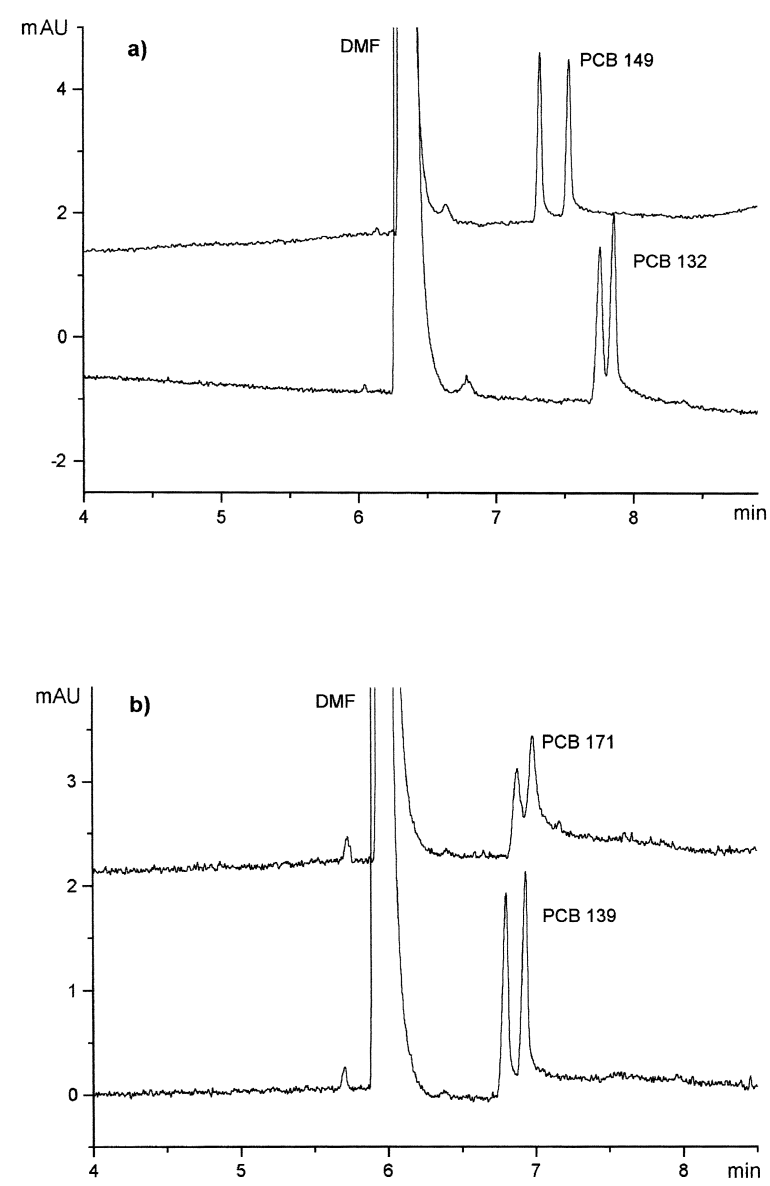

Fig. 4. Electropherograms corresponding to the chiral separation of PCBs 132, 149, 171 and 139 by CD-EKC using (a) $50 \mathrm{mM}$ MES buffer (pH 6.5), $2 M$ urea, $20 \mathrm{~m} M \mathrm{CM}-\gamma-\mathrm{CD}$, and $10 \mathrm{~m} M$ $\beta-\mathrm{CD}$ and (b) $50 \mathrm{~m} M$ MES buffer (pH 6.5), $2 M$ urea, $20 \mathrm{~m} M$ $\mathrm{CM}-\gamma-\mathrm{CD}$, and $5 \mathrm{~m} M \beta-\mathrm{CD}$. Other conditions as in Fig. 1.

\section{Conclusions}

The enantiomeric separation of chiral PCBs was not possible by CD-EKC using an anionic cyclodextrin alone (CM- $\beta-\mathrm{CD}$ or $\mathrm{CM}-\gamma-\mathrm{CD})$ as chiral pseudostationary phase in a MES buffer ( $\mathrm{pH}$ 6.5) with $2 M$ urea. The addition of a neutral cyclodextrin such as $\gamma$-CD (concentrations ranging from 20 to 40 $\mathrm{m} M$ ) in a MES buffer ( $\mathrm{pH}$ 6.5) with urea (2 $M$ ) containing $\mathrm{CM}-\boldsymbol{\gamma}-\mathrm{CD}$ as pseudostationary phase did not enable one to separate enantiomerically any chiral PCB. However, the employment of other neutral cyclodextrins $(\beta-\mathrm{CD}$ or PM- $\beta-\mathrm{CD})$ enabled the enantiomeric separation of several PCBs. Up to 12 of the 19 chiral PCBs stable at room temperature $(45,88,91,95,131,132,136,139,144,149,171$ and 176) were enantioresolved with $\beta-\mathrm{CD}$, while eight chiral PCBs $(45,88,91,95,131,136,144$ and 197) were enantiomerically separated with PM- $\beta$ $\mathrm{CD}$. This work presents for the first time the enantioresolution of the PCB 197 by CE, and although it was only partially resolved, similar resolutions were obtained by GC or HPLC but using very longer analysis times. In addition, although the chiral separations of the other PCBs have been reported by $\mathrm{CD}-\mathrm{MEKC}$, longer analysis times were required.

The best enantioresolutions were obtained with concentrations between 5 and $10 \mathrm{~m} M$ of $\beta-C D$ and $20 \mathrm{~m} M$ of PM- $\beta-C D$. On the other hand, in general, the enantioresolution of the chiral PCBs did not have a significant change when increasing the temperature (up to $60^{\circ} \mathrm{C}$ ) or the applied voltage (up to $25 \mathrm{kV}$ ), being $45^{\circ} \mathrm{C}$ and $20 \mathrm{kV}$ a good compromise among enantioresolution, analysis time, and current intensity.

Finally, multicomponent mixtures of chiral PCBs were enantiomerically separated by CD-EKC using $20 \mathrm{~m} M \mathrm{CM}-\gamma-\mathrm{CD}$ as pseudostationary phase in a MES buffer ( $\mathrm{pH}$ 6.5) with $2 M$ urea and $\beta-\mathrm{CD}$ or PM- $\beta-C D$ as chiral additive.

\section{Acknowledgements}

The authors thank the Comunidad Autónoma de Madrid (Spain) for project 07M/0049/1998.

\section{References}

[1] M.J. González, M.A. Fernández, L.M. Hernández, Arch. Environ. Contam. Toxicol. 20 (1991) 343.

[2] G. Font, J. Mañes, J.C. Moltó, Y. Picó, J. Chromatogr. A 733 (1996) 449.

[3] J. Faller, H. Hühnerfuss, W.A. König, R. Krebber, P. Ludwig, Environ. Sci. Technol. 25 (1991) 676.

[4] H.R. Buser, M.D. Müller, C. Rappe, Environ. Sci. Technol. 26 (1992) 1533.

[5] A. Glausch, J. Hahn, V. Schurig, Chemosphere 30 (1995) 2079.

[6] A. Glausch, G.P. Blanch, V. Schurig, J. Chromatogr. A 723 (1996) 399. 
[7] G.P. Blanch, A. Glausch, V. Schurig, R. Serrano, M.J. González, J. High Resolut. Chromatogr. 19 (1996) 393.

[8] P. Haglund, K. Wilberg, J. High Resolut. Chromatogr. 19 (1996) 373.

[9] W. Vetter, U. Klobes, B. Luckas, G. Hottinger, J. Chromatogr. A 769 (1997) 247.

[10] L. Ramos, L.M. Hernández, M.J. González, Anal. Chem. 71 (1999) 70.

[11] C.S. Wong, A.W. Garrison, J. Chromatogr. A 866 (2000) 213.

[12] B. Chankvetadze, Capillary Electrophoresis in Chiral Analysis, Wiley, Chichester, 1997.

[13] M.L. Marina, I. Benito, J.C. Díez-Masa, M.J. González, Chromatographia 42 (1996) 269.

[14] M.L. Marina, I. Benito, J.C. Díez-Masa, M.J. González, J. Chromatogr. A 752 (1996) 265.

[15] J. Grainger, Z. Liu, K. Marano, J. Barr, D.G. Patterson Jr., Organohalogen Comp. 31 (1997) 286.
[16] A.L. Crego, M.A. García, M.L. Marina, J. Microcol. Sep. 12 (2000) 33.

[17] A.L. Crego, M.J. González, M.L. Marina, Electrophoresis 19 (1998) 2113.

[18] B. Chankvetadze, J. Chromatogr. A 792 (1997) 269.

[19] G. Gübitz, M.G. Schmid, J. Chromatogr. A 792 (1997) 179.

[20] S. Fanali, J. Chromatogr. A 792 (1997) 227.

[21] M.J. Sepaniak, C.L. Copper, K.W. Whitaker, V.C. Anigbogu, Anal. Chem. 67 (1995) 2037.

[22] I.S. Lurie, J. Chromatogr. A 792 (1997) 297.

[23] K. Ballschmiter, M. Zell, Z. Fresenius, Anal. Chem. 302 (1980) 20.

[24] P. Haglund, J. Chromatogr. A 724 (1996) 219.

[25] E. Saint-Aman, D. Serve, J. Colloid Interface Sci. 138 (1990) 365.

[26] S. Terabe, Y. Miyashita, O. Shibata, E.R. Barnhart, L.R. Alexander, D.G. Patterson, B.L. Karger, K. Hosoya, N. Tanaka, J. Chromatogr. 516 (1990) 23. 